\title{
HABITAT SELECTION: OLFACTORY RESPONSE OF DROSOPHILA MELANOGASTER DEPENDS ON RESOURCES
}

\author{
A. A. HOFFMANN*, P. A. PARSONS* AND K. M. NIELSENं \\ * Department of Genetics and Human Variation, La Trobe University, Bundoora, Victoria \\ 3083, Australia † Genetics Department, Monash University, Clayton, Victoria 3064, Australia
}

Received 1.xi.83

\section{SUMMARY}

The behaviour of Drosophila melanogaster populations originating from three different fruit types (plums, peaches, apples) in the same orchard was compared in a wind tunnel olfactometer. After two generations of laboratory culture, flies tended to be attracted to the odours of the fruit type from which they originated. Thus, genetic variation for olfactory response affects habitats selected, and hence the microdistribution of $D$. melanogaster in the field.

\section{INTRODUCTION}

The potential importance of habitat selection within natural populations is being increasingly considered. For example, studies on pattern polymorphisms in snails (Jones, 1982; Johnson, 1981), moths (Boardman et al., 1974), and lizards (Schoener and Schoener, 1976) suggest that genotypes select habitats in which they are relatively fit. In Drosophila, enzyme and chromosome variants have been related to microhabitats (Taylor and Powell, 1977), although it is proving difficult to distinguish between genetic variation for habitat preference versus conditioning by habitat (Taylor and Powell, 1978; Shorrocks and Nigro, 1981). Considering resources, chromosomal variants have been associated with resource type (grapefruit vs. oranges) in $D$. melanogaster (Stalker, 1976), but enzyme variants could not be related to mushroom species in mycophagous Drosophila (Jaenike and Selander, 1979; Lacy, 1983).

Many of the above published studies are genotypic in approach, primarily considering gene (in particular electrophoretic) and chromosome polymorphisms. Interpretations tend to be difficult, since it is not necessarily simple to relate genotypic assessments to the field. The direct study of ecobehavioural traits important in determining the distribution and abundance of organisms in their habitats is an alternative, but more rarely considered approach (Parsons, 1983a); even so, there are studies suggesting that phototaxis in $D$. subobscura may be relatable to habitats in the wild (Kekic et al., 1980). Accordingly, here we consider the attraction of flies at the phenotypic level to resources found in nature.

\section{Materials AND MEthods}

Adults were collected as they emerged from apples, peaches, and plums taken from adjacent groves of an orchard, $35 \mathrm{~km}$ south east of Melbourne, Australia. Populations were set up from each fruit type, and maintained 
separately on a sucrose-agar-dead yeast laboratory medium for two generations. Olfactory response was tested by optomotor anemotaxis, the normal mechanism by which Drosophila responds to distant odours (Kennedy, 1977), using a vertical wind tunnel based on a design by Wright (1966), fig. 1. An experiment consisted of the release of four hundred flies (mixed sexes)

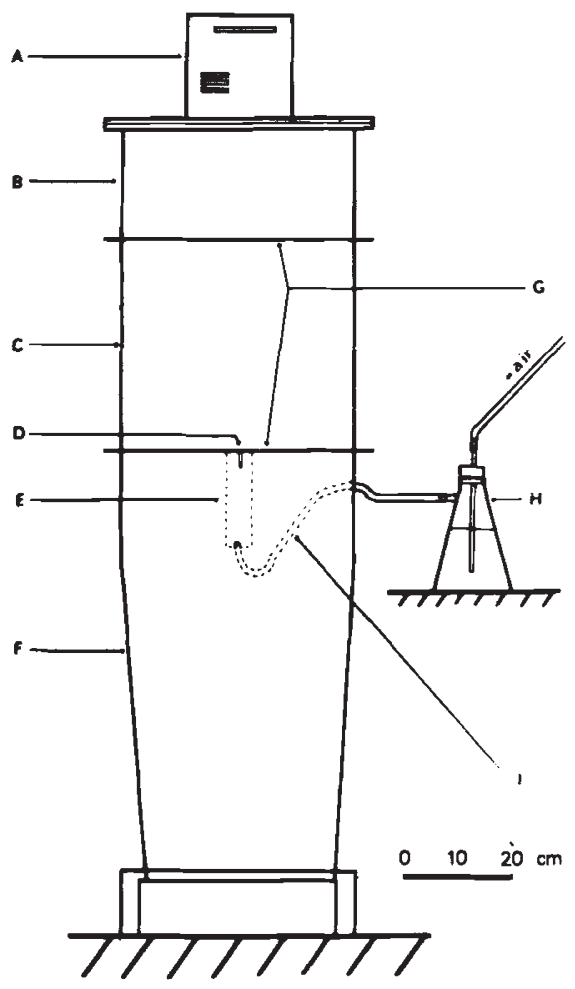

FIG. 1. Wind tunnel olfactometer based upon a design by Wright (1966). The apparatus was constructed from white perspex, and comprised three sections: an upper section (B) supporting an exhaust fan (A), an observation chamber $(C)$, with clear perspex on one side and gauze at both ends (G) and a lower section (F) on a stand into which $320 \mathrm{ml}$ cylinders (E) were suspended; these cylinders were covered with gauze at the lower end, the entry of flies being permitted through a small plastic funnel ( $4 \mathrm{~mm}$ at entrance, reducing to $3 \mathrm{~mm}$ ) (D) extending through the lower gauze of the observation chamber (C). Air was passed into flasks $(\mathrm{H})$ containing odorants and carried to trap cylinders via silicone tubes (I).

from each of two "fruit type" populations in this tunnel. The populations were tested in the three possible combinations with the odorants of their respective fruit types (table 1). Flies were 2-3 days old, and were starved for 23-24 hours at $20^{\circ} \mathrm{C}$ under high humidity before being released into the observation chamber (C). The populations were marked with fluorescent dusts, colours being alternated between experiments. The odorants were prepared by filtering the liquid fraction of pulp from mature fruits of each fruit type, and diluting 1 in 10 parts with distilled water. Air cleaned with silica gel and charcoal was passed at $30 \pm 5 \mathrm{ml}$ per minute into conical flasks 


\section{TABLE 1}

Response of D. melanogaster populations collected from different fruits to fruit attractants in the wind tunnel olfactometer, after culturing for two generations on laboratory medium

\begin{tabular}{|c|c|c|c|}
\hline \multirow[t]{2}{*}{ Attractant } & \multicolumn{2}{|c|}{ Population } & \multirow[t]{2}{*}{$\begin{array}{c}x^{2} \text { Contingency } \\
\text { (df } 1)\end{array}$} \\
\hline & peach & plum & \\
\hline peach & $174(154 \cdot 7)$ & $133(152 \cdot 2)$ & \\
\hline plum & $71(90 \cdot 2)$ & $108(88 \cdot 8)$ & $13 \cdot 09^{* *}$ \\
\hline peach & $221(208 \cdot 6)$ & $183(195.4)$ & \\
\hline plum & $127(139.4)$ & $143(130 \cdot 6)$ & $3 \cdot 81$ \\
\hline peach & $159(135 \cdot 6)$ & $47(70.4)$ & \\
\hline plum & $101(124 \cdot 4)$ & $88(64 \cdot 6)$ & $24 \cdot 70^{* *}$ \\
\hline peach & $151(139 \cdot 0)$ & $128(140 \cdot 0)$ & \\
\hline \multirow[t]{2}{*}{ plum } & $138(150 \cdot 0)$ & $163(151 \cdot 0)$ & $5 \cdot 56^{*}$ \\
\hline & & Composite & $x^{2} 47 \cdot 16^{* *}(\mathrm{df} 4)$ \\
\hline & plum & apple & \\
\hline plum & $212(184 \cdot 2)$ & $159(186 \cdot 8)$ & \\
\hline apple & $64(91.8)$ & $121(93 \cdot 2)$ & $25 \cdot 11^{* *}$ \\
\hline plum & $196(192 \cdot 3)$ & $184(187 \cdot 7)$ & \\
\hline apple & $176(179 \cdot 7)$ & $179(175 \cdot 3)$ & 0.29 \\
\hline plum & $181(169 \cdot 4)$ & $123(134 \cdot 6)$ & \\
\hline \multirow[t]{3}{*}{ apple } & $125(136 \cdot 6)$ & $120(108 \cdot 4)$ & $3.99^{*}$ \\
\hline & & Composite & $x^{2} 29 \cdot 39^{* *}($ df 3$)$ \\
\hline & apple & peach & \\
\hline apple & $150(144 \cdot 8)$ & $70(75 \cdot 2)$ & \\
\hline peach & $81 \quad(86 \cdot 2)$ & $50(44 \cdot 7)$ & 1.47 \\
\hline apple & $145(138.4)$ & $122(128 \cdot 6)$ & \\
\hline peach & $136(142 \cdot 6)$ & $139(132 \cdot 4)$ & $0 \cdot 28$ \\
\hline apple & $169(165 \cdot 0)$ & $146(150 \cdot 0)$ & \\
\hline \multirow[t]{2}{*}{ peach } & $229(233.0)$ & $216(212.0)$ & 0.35 \\
\hline & & Composite & $\chi^{2} 2 \cdot 10($ df 3$)$ \\
\hline
\end{tabular}

* $P<0.05$; ** $P<0.01$.

Chi square contingency values test for independent association. Numbers in brackets are expected values.

(G) containing the odorants, and the odours released at the base of trap cylinders (D). Light was provided by a single fluorescent tube (40 Watt) placed vertically behind the tunnel. Experiments were set up between 1700 and 1800 hours, and flies were collected 5 hours later from the trap cylinders.

\section{Results}

There is a consistent tendency for flies to be attracted to odours of fruit types from which they originated (table 1), which is significant for three of the four peach-plum experiments, and two of the three plum-apple experiments. The composite $\chi^{2}$ values are significant for these fruit combinations, although there is significant heterogeneity among the trials (peach-plum, $\chi^{2}=14.61$, df $3 P<0.01$; plum-apple, $\chi^{2}=13.69$, df $2, P<0.01$ ); this suggests that the odour preferences may be sensitive to slight changes in environmental conditions or odour composition. The apple-peach experiments show the same trend, although the data are not statistically significant. 


\section{Discussion}

Since all files were cultured under a uniform laboratory environment, these findings suggest that variation in the attraction of $D$. melanogaster to different resources is genetic. While non-Mendelian inheritance cannot be absolutely discounted, maternal effects for olfactory response in $D$. melanogaster have not been found (Fuyama, 1978).

The apple, plum and peach resources are available simultaneously in Melbourne orchards for two to three months annually, so that selection for differential resource utilisation may be quite strong during this period. This variation may contribute to the more efficient utilisation of resources by genotypes, and as a consequence the persistence of genetic variation in natural populations (Taylor, 1976).

The present findings on olfactory response indicate the usefulness of a phenotypic approach to habitat selection (Parsons, 1983a, 1983b). Quantitative phenotypic variation in the selection of environmental components of a heterogeneous habitat needs to be assessed and related to fitness. Habitat choice assumes that phenotypes avoid areas of the environment in which they are least fit, and congregate where their fitnesses are greatest. More generally, the penotypic approach tends to place habitat selection studies on the interface of ecology and quantitative genetics compared with the genotypic approach which predominantly considers the interface of ecology and population genetics. The two approaches converge where discrete genotypes can be followed in nature as in pattern polymorphisms (e.g., Jones, 1982; Schoener and Schoener, 1977).

Acknowledgements. We are grateful to Dr J. S. Jones for helpful discussions.

\section{REFERENCES}

BOARDMAN, M., ASKEW, R. R. AND COOK, L. M. 1974. Experiments on resting site selection by nocturnal moths. J. Zool., Lond., 172, 343-355.

FUYAMA, Y. 1978. Behaviour genetics of olfactory response in Drosophila. II. An odorantspecific variant in a natural population of Drosophila melanogaster. Behav. Genet., 8 , $399-414$.

JAENIKE, J. AND SELANDER, R. K. 1979. Enforced generalism in mycophagous Drosophila : Genetic evidence. Evolution, 33, 741-749.

JOHNSON, M. S. 1981. Effects of migration and habitat choice on shell banding frequencies in Theba pisana at a habitat boundary. Heredity, 47, 121-133.

JONES, J. S. 1982. Genetic differences in individual behaviour associated with shell polymorphism in the snail Cepaea nemoralis. Nature, 298, 749-750.

KEKIC, V., TAYLOR, C. E. AND JELKOVIC, M. 1980. Habitat choice and resource specialization by Drosophila subobscura. Genetika 12, 219-225.

KENNEDY, J. S. 1977. Olfactory responses to distant plants and other odour sources. In Shorey, H. H. and McKelvey, J. J. (eds.) Chemical Control of Insect Behaviour: Theory and Application, Wiley and Son, New York, pp. 67-91.

LACY, R. 1983. Structure of genetic variation within and between populations of mycophagous Drosophila. Genetics, 104, 81-94.

PARSONS, P. A. $1983 a$. Ecobehavioural genetics: habitats and colonists. Ann. Rev. Ecol. Syst., $14,35-55$.

PARSONS, P. A. 1983b. The Evolutionary Biology of Colonizing Species. Cambridge University Press, New York.

SCHOENER, T. W. AND SCHOENER, A. 1976. The ecological context of female pattern polymorphism in the lizard Anolis sagrei. Evolution, 30, 650-658.

SHORROCKS, B. AND NIGRO, C. 1981. Microdistribution and habitat selection in Drosophila subobscura. Biol. J. Linn. Soc., J6, 293-301. 
STALKER, H. D. 1976. Chromosome studies in wild populations of Drosophila melanogaster. Genetics, 82, 323-347.

TAYLOR, C. E. 1976. Genetic variation in heterogeneous environments. Genetics, 83, 887-894. TAYLOR, C. E. AND POWELL, J. R. 1977. Microgeographic differentiation of chromosomal and enzyme polymorphisms in Drosophila persimilis. Genetics 85, 681-695.

TAYLOR, C. E. AND POWELL, J. R. 1978. Habitat choice in natural populations of Drosophila. Oecologia, 37, 69-75.

WRIGHT, R. H. 1966. An insect olfactometer. Canad. Entomol., 98, 282-285. 